\title{
Largest democracy in the world crippled by COVID-19: current perspective and experience from India
}

\author{
Rahil Changotra ${ }^{1} \cdot$ Himadri Rajput ${ }^{1} \cdot$ Prachi Rajput $^{2} \cdot$ Sneha Gautam $^{3}$. \\ Amarpreet Singh Arora ${ }^{4}$ (D)
}

Received: 31 July 2020 / Accepted: 26 August 2020 / Published online: 31 August 2020

(c) Springer Nature B.V. 2020

\begin{abstract}
The outbreak of novel and recent coronavirus disease 2019, caused by the severe acute respiratory syndrome coronavirus 2 (SARS-CoV-2) virus, has made an emergency throughout the world. In India, the outspread of the pandemic was observed on 3 March 2020, and after that exponential growth in the cases was observed in the country. Owing to the widespread transmission, high population density, high testing capacity and ineffective treatment, a continuous rise in cases was observed due to the pandemic in India. In this paper, we have discussed the trend and spread of COVID-19 spread in India with time, history of initial confirmed cases, the impact of phased manner lockdown, age- and gender-wise trend of cases and comparison of cases with the other most affected countries. The study uses exploratory data analysis to describe the current situation of COVID-19 cases in India till 16 August 2020, with the help of data from the Ministry of Health and Family Welfare, Government of India (GOI) and the World Health Organization (WHO). As of August 16, the total number of confirmed cases in India crossed 2.5 million marks with over 50,000 causalities. With more patients recovering and being discharged from hospitals and home isolation (in case of mild and moderate cases), the total recoveries have crossed the 1.8 million mark with a recovery rate of more than $70 \%$ and case fatality rate of $1.94 \%$ which is maintained below the global average and is on a continuous positive slide. The study also enlightens the preventive and stringent measures taken by India to combat the COVID-19 situation along with the future prospects. The GOI is following its proactive and preemptive approach for management, prevention and containment of COVID-19 in collaboration with the WHO.
\end{abstract}

Keywords Coronavirus · COVID-19 $\cdot$ Pandemic $\cdot$ Public health $\cdot$ Trend analysis $\cdot$ India

Electronic supplementary material The online version of this article (https://doi.org/10.1007/s1066 8-020-00963-z) contains supplementary material, which is available to authorized users.

Rahil Changotra

changotrarahil@gamil.com

$\bowtie$ Amarpreet Singh Arora

amarpreet.amar007@gmail.com

Extended author information available on the last page of the article 


\section{Introduction}

On 30 January 2020, World Health Organization (WHO) declared the severe acute respiratory syndrome coronavirus 2 (SARS-CoV-2) epidemic, a Public Health Emergency of International Concern (WHO 2020). SARS-CoV-2, which is also named as coronavirus disease 2019 (COVID-19), is a novel and highly contagion virus that belongs to the family of "Nidovirus" which includes "Roiniviridae", "Artieviridae" and "Coronavirdae" family, causing respiratory illness in humans with symptoms such as common cold and fever to more acute diseases like and Middle East Respiratory Syndrome (MERS) and Severe Acute Respiratory Syndrome (SARS) (De Wit et al. 2016; Din and Boppana 2020; Arora et al. 2020). The coronavirus is an envelope positive sense single-stranded RNA virus whose genome is mainly comprised of nearly 30,000 nucleotides with genome size varied in between 26 and $36 \mathrm{~kb}$, and its replication and transcription depend on the replicase gene which encodes two overlapping polyproteins, pp1a and pp1ab (Zhou et al. 2020; Wu et al. 2020). The whole-genome level of coronavirus is $96 \%$ match with a bat coronavirus (Zhou et al. 2020). The diameter of coronavirus ranges from 60 to $140 \mathrm{~nm}$ with club-shaped spikes forming a crown-like structure on its surface under an electron microscope, hence the name given coronavirus (Richman et al. 2016). On 11 March 2020, WHO declared the outbreak of COVID-19 a pandemic because of its worldwide spread and severe impact on the human population. The cause of the disease outbreak is still unknown, but it was first detected on 30 December 2019, in Wuhan, Hubei province of China, as a local outbreak of pneumonia cases due to some unknown cause (Wu et al. 2020; Zhu et al. 2020; Li et al. 2020). Although the outbreak was likely to be associated with the large seafood market leading to a zoonotic transmission event, soon it became clear that human-to-human transmission was occurring at an extensive rate. With the 2 months of the outbreak, the pandemic spread throughout the world with an alarming speed. As of 1 March 2020, 87,137 confirmed cases and 2,997 deaths had been reported globally by the WHO due to COVID19 (WHO 2020a), and it affected 58 countries (WHO 2020a). The number of infected patients and deaths caused by this pandemic is on a constant rise across the globe, and it has also caused a major shock to an already fragile global economy (Rajput et al. 2020).

Coronavirus is a "communicable" disease, and its spread all over the world is entirely associated with human-to-human transmission rather than transmission through the air. However, the transmission of coronavirus through airborne spread (i.e., from aerosol particles, particulates matter etc.) has also been believed to be the source of transmission (WHO 2020b; Wathore et al. 2020; Bherwani et al. 2020). Due to its small size, it can enter the body via droplets from mouth or nose during close and unprotected contact between an infector and infectee. It has also been observed that coronavirus-infected people develop symptoms and signs, including mild respiratory illness, fever, dry cough and tiredness, with a mean incubation period of 5 days (Li et al. 2020), which can also range up to 14 days (WHO 2020b). Predominantly, the disease presentation can also range from no symptoms (asymptomatic) to severe pneumonia and even death (WHO 2020b). Recent studies showed that the number of infected individuals with the novel COVID-19 may get double every 7 days and each person could spread this virus to 2.2-3.58 persons on an average (Chan et al. 2020). The individuals $\geq 60$ years of age and with chronic underlying health conditions are at a greater risk of being infected with COVID-19 compared to the children who might have less probability to get infected or, if so, these children may show mild symptoms or may have asymptomatic infection (Sun et al. 2020; Li et al. 2020). Practicing hand (with alcohol-based gel or sanitizer) and respiratory hygiene and maintaining 
a physical distance of at least 3 feet $(1 \mathrm{~m})$ are the best way to protect yourself and others from the novel COVID-19 (WHO 2020b). In an interim guidance report by WHO, wearing a proper mask is also a preventive measure that could reduce the spread of various respiratory viruses, including COVID-19 (WHO 2020c). Importantly, the use of masks alone does not offer enough protection, and thus, it should be combined with protective measures such as hand hygiene and physical distancing. Currently, the respiratory face masks that are being used worldwide include, N95 (USA code), KF94 (South Korea code), KN95 (China code) and FFP2 (EU code, including the UK). Generally, all these respirable face masks are the same as they stop $95 \%$ of droplets and viruses $>0.3$ microns in size (Fig. 1). Figure 1 shows that wearing masks could forbid the entrance of various respirable particles, including the COVID-19 virus (encapsulated in water droplets), and could help to reduce the spread of COVID-19 through transmission of droplets from sneezing, coughing and fluids from infected peoples to others. The diameter of water droplets containing infectious virus could range from 0.5 (with a float time of $21 \mathrm{~h}-21$ days in the air) to 100 microns (with a float time of $6 \mathrm{~s}$ in the air) (Robertson 2020; CDCP 2020; Gupta et al. 2020). Besides, cleaning surfaces with an alcohol-based disinfectant is also important to stop the COVID-19 spread as it can survive on the surfaces such as copper (up to $4 \mathrm{~h}$ ), stainless steel and plastic $(\sim 72 \mathrm{~h})$ and cardboard $(\sim 24 \mathrm{~h})$ (WHO 2020b). Some of the countries have adopted the early isolation of infected patients and quarantine policies to prevent the transmission from the travelers who have returned from the COVID-19-infected countries (Hellewell et al. 2020). As of 1 June 2020, there is no antiviral medicine and no vaccine to treat COVID-19 (WHO 2020b).

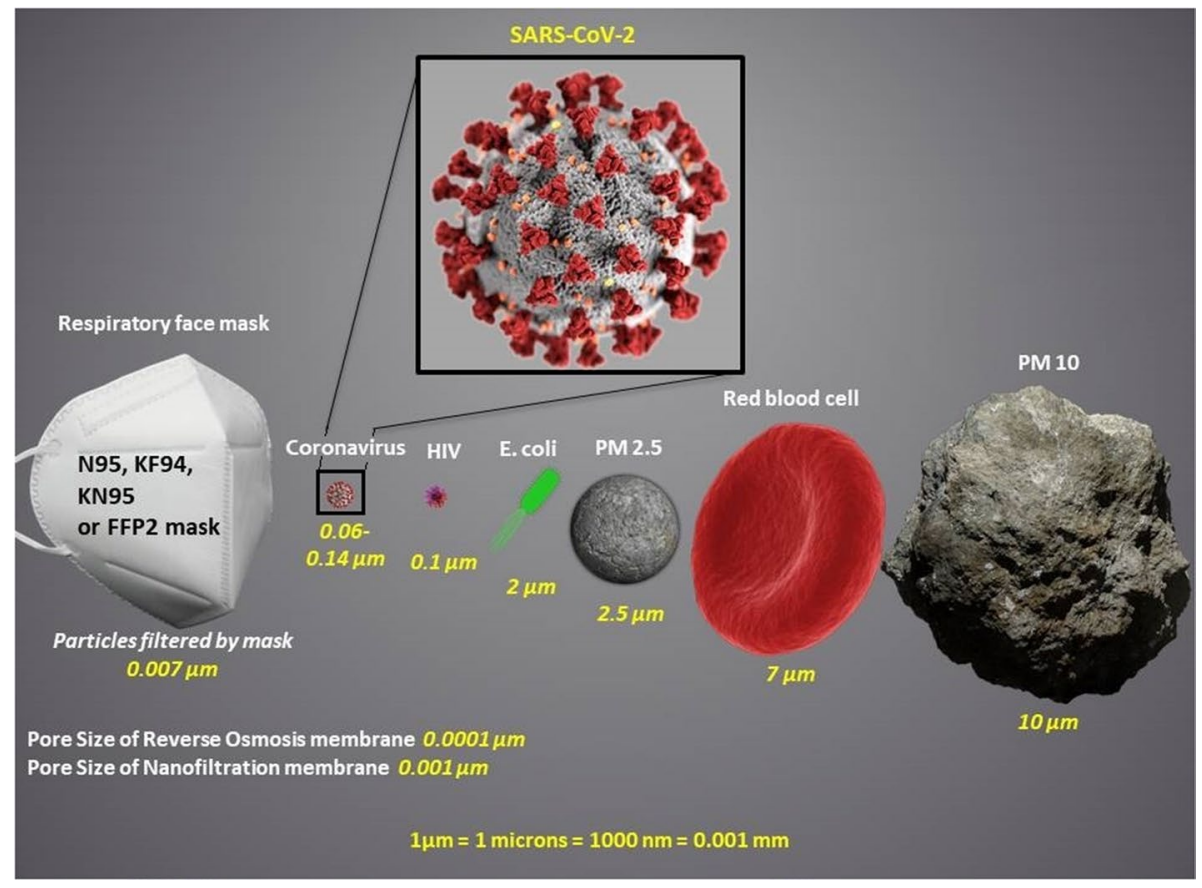

Fig. 1 Size reference chart of COVID-19 ( Source: MoHFW, GOI and SARS-CoV-2 image from Centre for Disease Control and Prevention) 


\section{COVID-19 spread in India}

On the same day when COVID-19 was declared as a Public Health Emergency of International Concern by WHO, i.e., 30 January 2020, India reported its first COVID-19 case in Kerala. This was linked to a student who came from Wuhan, China (considered to be the epicenter of COVID-19), and since then there is an exponential growth of COVID-19 cases in India. As of 3 May 2020, 40,263 of total confirmed cases, and 1306 deaths had been reported by the Ministry of Health and Family Welfare, Government of India (GOI) (WHO 2020d; MoHFW, GOI). The GOI has taken several preventive measures to curb the spread by implementing social distancing and awareness regarding the novel COVID-19. Considering the worldwide impact of COVID-19, the GOI imposed nationwide lockdown in a phased manner to curb the COVID-19 crisis. Since the lockdown, containing the virus through the transmission mechanism in a largely populated country like India has been a subject of great concern. Within the large and diverse populated country like India, it is not at all feasible to impose proper lockdown (quarantine) to all the susceptible population. Only a certain percentage of the population could be successfully quarantined during the lockdown periods. In the last few months, there has been renewed interest in the questions largely associated with the COVID-19 and its alarming presence on a global scale. Many researchers have already discussed the effect of factors like temperature (Wang et al. 2020a, b), humidity (Luo et al. 2020; Wang et al. 2020a), climatic conditions (Araujo and Naimi 2020) and latitude analysis (Sajadi et al. 2020) on the transmission of COVID-19. Studies suggested that relative humidity $\geq 80 \%$ and a temperature of $37^{\circ} \mathrm{C}$ (for 1 day) or $56^{\circ} \mathrm{C}$ (for $30 \mathrm{~min}$ ) neutralize the COVID-19 virus (Chin et al. 2020). The reported studies are based on preliminary correlation-based information, laboratory-based medical/biological analysis and experimentations related to the virus, and thus, more precise evidence is required to achieve the conclusions. Till now, several data-driven modeling studies have been performed by different research groups to study the impact of COVID-19 outbreaks globally (Chen et al. 2020; Kucharski et al. 2020; Tang et al. 2020; Shen et al. 2020). In the Indian context, a similar analysis has been performed by various authors using epidemiological models on interventions like social distancing (Ranjan 2020; Singh and Adhikari 2020), space-time dependence analysis on the outbreak (Biswas and Sen 2020) and analysis on the estimation of infected persons in Indian hot-spots using fatality data (Gupta and Shankar 2020). Data-driven assessment of any infectious disease could play a key role in the estimation of the outbreak in particular location and time, forecasting for future outbreaks and determining the efficiency of control measures taken to curb the spread of disease.

\section{COVID-19 India's data analysis}

In this study, we have formulated an "Exploratory Data Analysis" to account for the impact of four-phase (Phase I, II, III and IV) lockdown on the transmission of COVID-19 cases in India. Exploratory Data Analysis (EDA) is a revelatory step to any kind of analysis based on the data sets. Assessment of changes in cases with time can give insightful information on the epidemiological situation and ascertain whether the protective measures to control the disease are having a quantifiable effect (Riley et al. 2003; Funk et al. 2017). In this paper, we will discuss about the trend and spread of COVID-19 in India 
with time by considering the different factors. For this purpose, we have used the COVID19 data from the website of the Ministry of Health and Family Welfare (MoHFW, GOI), the Indian Council of Medical Research (ICMR, GOI), John Hopkins GitHub repository (JHGR, USA) and Coronavirus Worldometer (CoVW 2020. The data were used to explore the pattern of COVID-19 cases in India and compared it with a pattern of cases in the most affected countries in the world. The data were collected, organized and processed in the form of graphical representation for the better visualization of results. The total number of confirmed cases, deaths, active and recovered cases as of 16 August 2020 (IST 01:00 PM), as well as the case distribution by age-, gender- and province-wise were also presented. The trend and spread of COVID-19 future in India have also been included with respect to reproduction number, doubling time, fatality rate, mortality rate and recovery rate. At last, the preventive and stringent measures taken by the GOI to combat the outbreak of COVID19 have been discussed.

\subsection{History of COVID-19 in India}

The first COVID-19 case in India was linked to the person who had a travel history to China, which has reported a high quantity of cases in the initial stage of the pandemic. Later, the cases in India were reported as a result of local transmission due to human-tohuman contact. Figure 2 shows the travel history of the first 100 patients of COVID-19 in India. These analyses indicate that out of 100 patients, 68 patients had a travel history to a country which was already affected by the outbreak of COVID-19, and the remaining 32 patients had contracted the disease through local transmission in India (MoHFW, GOI).

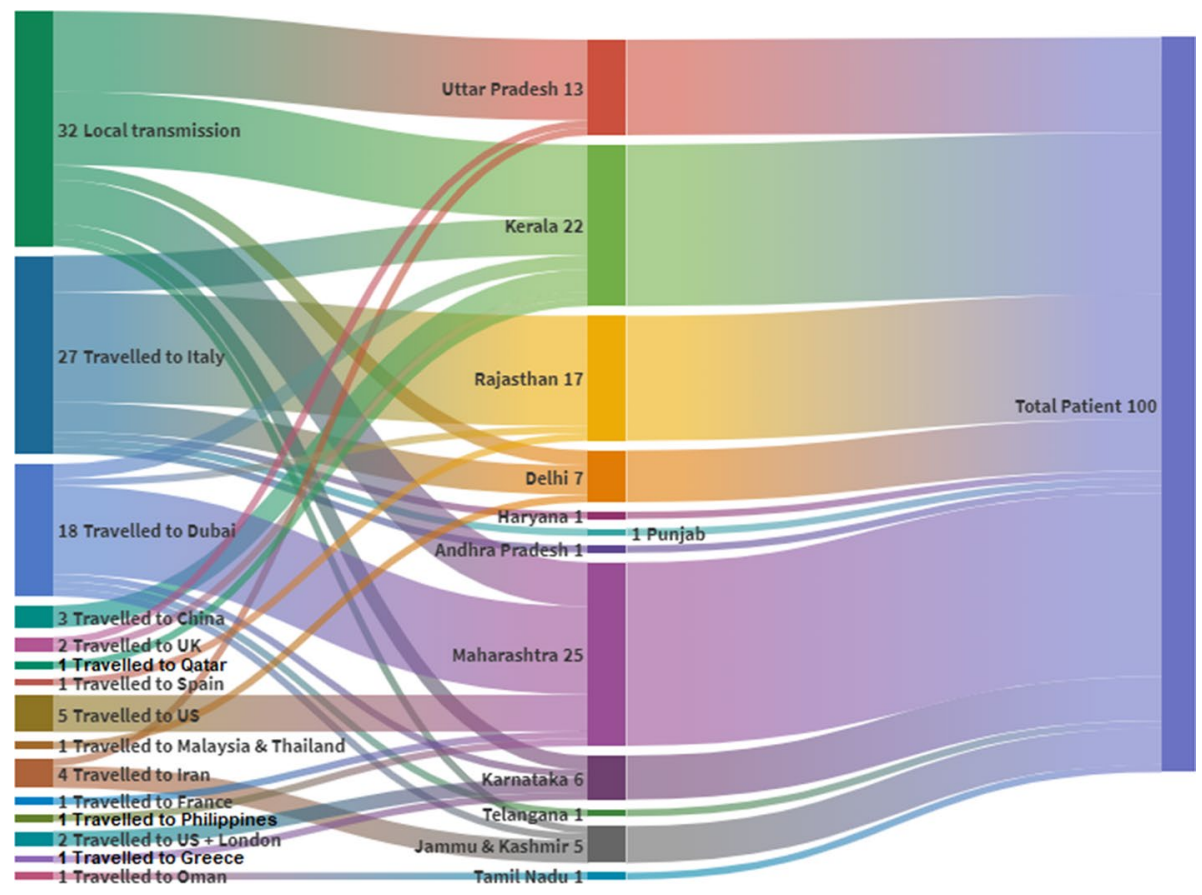

Fig. 2 Travel histories of first 100 patients of COVID-19 in India ( Source: MoHFW, GOI) 
Among the first 100 patients in India, 27\% of the patients had a travel history to Italy and $21 \%$ of the infected person from Italy has further contracted the disease to Rajasthan State of India (MoHFW, GOI). On 30 January 2020, the Ministry of Civil Aviation and MoHFW issued an advisory-related travel to avoid the non-essential travel to China and also initiated the screening for cough and fever of travelers coming to India from China.

\subsection{Spread of pandemic in India over time}

From the first detected patient on 30 January 2020 to 1 March 2020, when the third patient was reported, all the 3 confirmed cases in Kerala were recovered and were primarily associated to have an overseas travel history. At that time, the world was on the verge of facing a continued surge in the COVID-19 outbreak with total confirmed cases of 87,137 and 2,997 deaths reported globally by the WHO. In this regard, the GOI issued travel advisories in February 2020 to refrain the traveling of peoples to most affected countries including China, Italy, Iran and the Republic of Korea, and people coming to India from these countries to be quarantined for 14 days. Following March 3, an exponential surge in the confirmed cases was observed in a short period in India. Figure 3 a shows the cumulative and daily trend of total confirmed COVID-19 cases in India. Figure $3 \mathrm{~b}$ shows the cumulative and daily trend of total deaths due to COVID-19 in India. The daily and cumulative trend of active and recovered cases of COVID-19 in India is presented in Fig. S1 (supplementary information). Since no new case was observed between January 31 and March 2, the trend of COVID-19 cases in Fig. 3 has been shown starting from 1 March 2020. The rise of COVID-19 case in India can be observed from the figure that as on 10 March 2020, the total number of confirmed cases was 63, and on 20 March 2020, the confirmed cases rise to 256; by the end of March, Indian had a total of 1635 confirmed cases of COVID19; and by the end of June, COVID-19 cases in India crossed the mark of 500,000. This finding suggests that the COVID-19 cases in India rise rapidly with an average confirmed case of 10-73 per day from the first to the 300th case in India. To monitor and enhance the preparedness and containment of the virus, COVID-19 was declared as a "notified disaster" under the Disaster Management Act 2005 (WHO 2020e) by the GOI and imposed 3 weeks nationwide lockdown (Phase I) starting from 25 March 2020. Considering the global impact of COVID-19, the GOI extended the lockdown till May 3, for 20 days (Phase II). After the comprehensive reviews and considering the rise in cases of COVID-19 in the view of lockdown measures, the GOI on May 4, extended the lockdown till May 17, for 14 days (Phase III) followed by the Phase IV of lockdown till 31 May 2020. Considering the staggering rise in the cases due to the pandemic, Phase $\mathrm{V}$ of lockdown was imposed from 1 June to 30 June 2020 with some relaxations for non-containment zones. Although the GOI imposed a travel restriction on international incoming flights, railways and interstate movement with the lockdown for containment of COVID-19, the local transmission and transmission from overseas travelers were occurring leading to a substantial increase in the confirmed cases of COVID-19.

Owing to the widespread transmission, high population density and ineffective treatment of COVID-19, continuous rise in cases was observed due to pandemic as shown in Fig. 3. Despite effective vaccination, social distancing has been regarded as the most commonly used prevention and control strategy (Ferguson et al. 2020). Although the purpose of lockdowns was to promote the social distancing, the analysis showed that nationwide lockdowns had not improved the COVID-19 situation in India. As of 16 August 2020 (IST 01:00 PM), the total number of COVID-19 cases in India crosses 2.5 million $(25,94,112)$ 


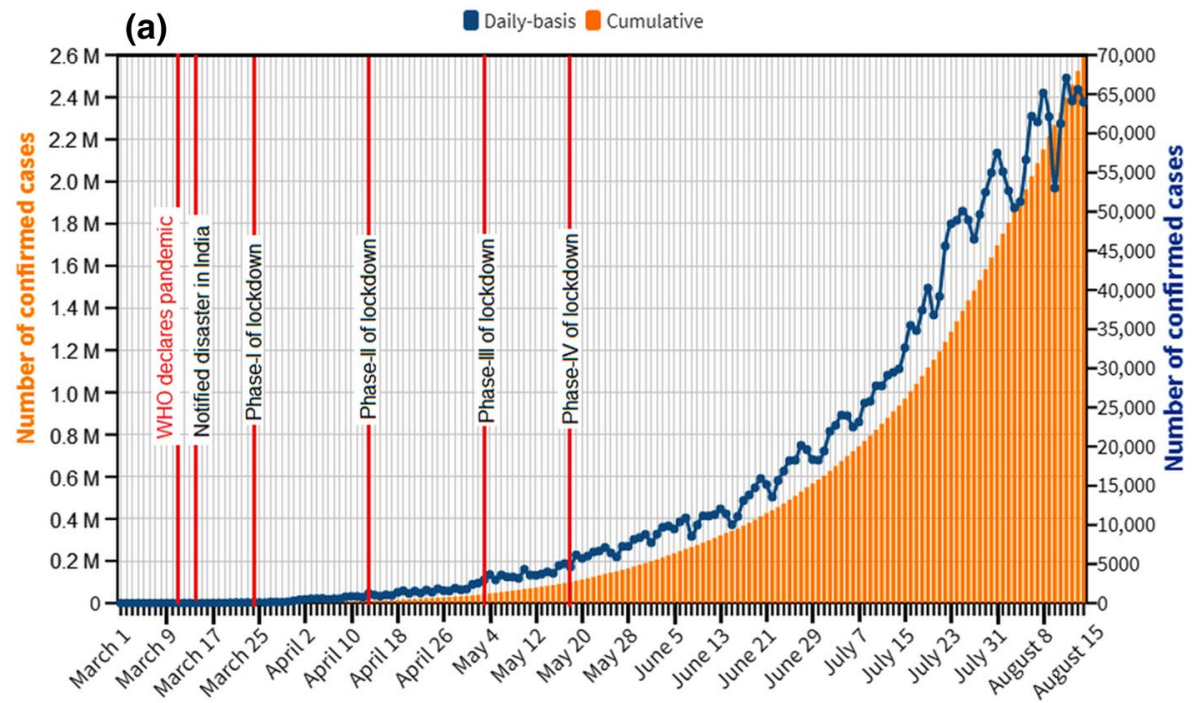

(b)

Daily-basis Cumulative

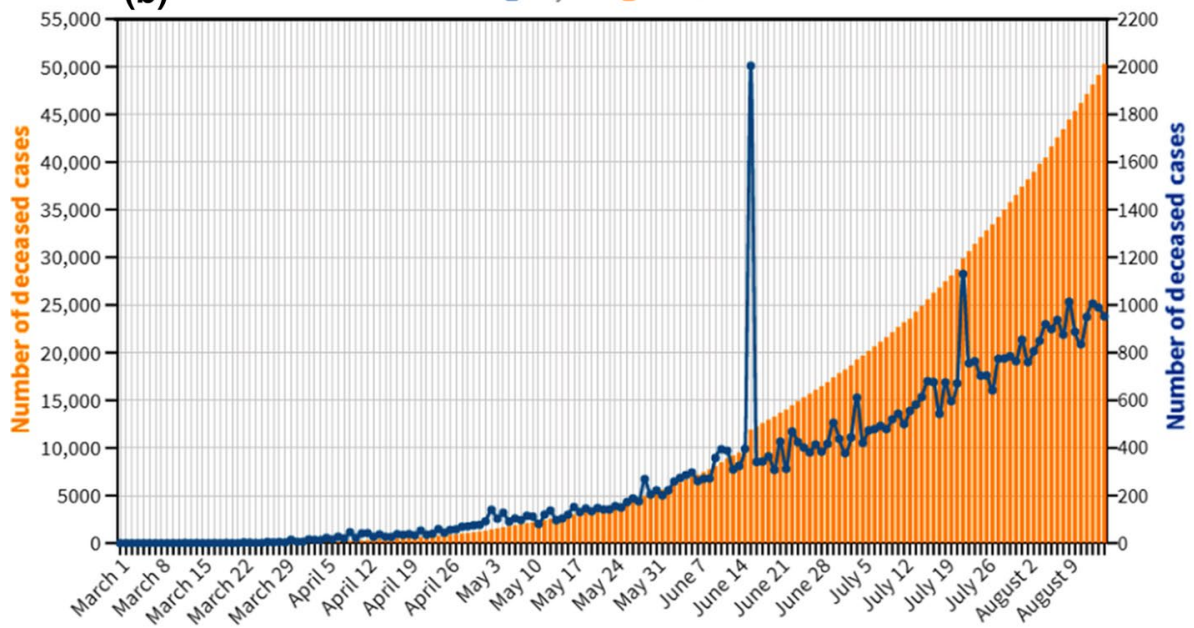

Fig. 3 Cumulative and daily basis a confirmed cases and $\mathbf{b}$ deaths due to COVID-19 in India over time as of 15 August 2020 ( Source: MoHFW, GOI)

including 18,62,937 who have been cured/recovered and 50,122 deceased. Till August 15, the active number of cases in India is 680,561. Currently, the confirmed cases in India are rising with 60,000 average cases per day, along with the improvement in the recovery rate. According to the MoHFW, the recovery rate in India was $7.1 \%$ when the Phase I lockdown started, the recovery rate during the Phase II of lockdown was $11.42 \%$, and it then rose to $26.59 \%$ in Phase III. As of May 31 (end of Phase IV of lockdown), the recovery rate in India is reported to be $48.19 \%$, and at present, the recovery rate in India is more than $70 \%$ (as of 15 August 2020). According to the Indian Statistical Institute (ISI 2020), the lockdown has averted around 20 lakhs cases and 54,000 deaths due to COVID19 , suggesting that lockdown could have acted as a potent social vaccine. As reported by the Public Health Foundation of India (PHFI 2020), nearly 78,000 lives have been saved 
due to lockdown, and with the anticipation that Phase IV lockdown will be lifted after May 31 , the rise in several cases may reach its peak in mid-July. These analyses suggested that this trend in the COVID-19 transmission could be due to higher percentage of COVID-19 spreaders which further deteriorated the situation in India. The study conducted by ICMR showed that the nationwide lockdown imposed by GOI was successful to prevent the rapid spread of COVID-19 and keeping the transmission of COVID-19 low in India. ICMR has also suggested that the risk of transmission is 1.89 and 1.09 times higher in urban slums and areas, respectively, compared to the rural areas. The other probable reason for daily basis rise of COVID-19 cases in India could be due to the ramp-up of testing to 8 lakh test per day, which is 95 times higher than what it was at the beginning of April (MoHFW, GOI). It is expected that the more cases are bound to rise due to the rise in a testing capacity. However, the lockdown could help in the containment of the pandemic and dipping the COVID-19 cases in India where the population of symptomatic patients is higher. But the contribution of COVID-19 cases arising from asymptomatic patients could also not be neglected.

According to the MoHFW, among the initial confirmed cases of 10,694, males account for $64.9 \%$ and females for $35.1 \%$ (Table 1, supplementary information). Table 1 (supplementary information) shows the age distribution of infected males and females due to the pandemic in India. The data display that the maximum numbers of confirmed cases (46.18\%) are from the peoples in the age group of 20-40 years, and only $10.3 \%$ of confirmed cases are from the age group $\geq 60$ years (MoHFW, GOI).

\subsection{COVID-19 cases in India versus other countries}

In January 2020, when the pandemic started spreading across the globe, the initial phase saw India with no new case till 2 March 2020. But soon within 2-3 weeks, India encountered the exponential growth of COVID-19 through the local transmission and transmission from overseas travelers. Even though GOI imposed strict nationwide and overseas travel restriction through a rigorous approach of lockdown, pandemic continues to spread all across the country. As of 15 August 2020 (IST 11:59 PM), as shown in Fig. 4a, India has witnessed $12 \%$ of the COVID-19 cases being reported worldwide, with USA reporting one-fourth of the total number of cases. The world is now witnessing the biggest pandemic, with the total confirmed cases exceeding $21.6 \mathrm{M}$ and death exceeding 7.5 lakhs till date. The number of causalities in India stands at $6.5 \%$ (Fig. 4b) on a global scale. At present, there are only two countries (USA and Brazil) in the world having more COVID-19 cases than India. Table 2 (supplementary material) provides detailed information on the COVID19 cases around the world, with USA and Europe being affected the most in terms of causalities and the number of infected patients. Although India reported its first COVID-19 case in an early stage than the other South-Asian countries, however owing to the large population density and massive population, the number of cases seems to grow exponentially now; even surpassing the total confirmed cases of China (the epicenter of the pandemic). Compared to countries like UK, Spain, Germany and Italy that have eased lockdown, the densely populated country like India has witnessed the lowest COVID-19 cases per million populations, at 1875 cases per lakh when compared to 2773 cases per million populations for the world in total (WHO 2020f). Similarly, the mortality/million population in India is 36 deaths/lakh populations, which is lowest in comparison to the global case mortality rate of 98.7 deaths per lakh population (MoHFW, GOI). The relatively low 


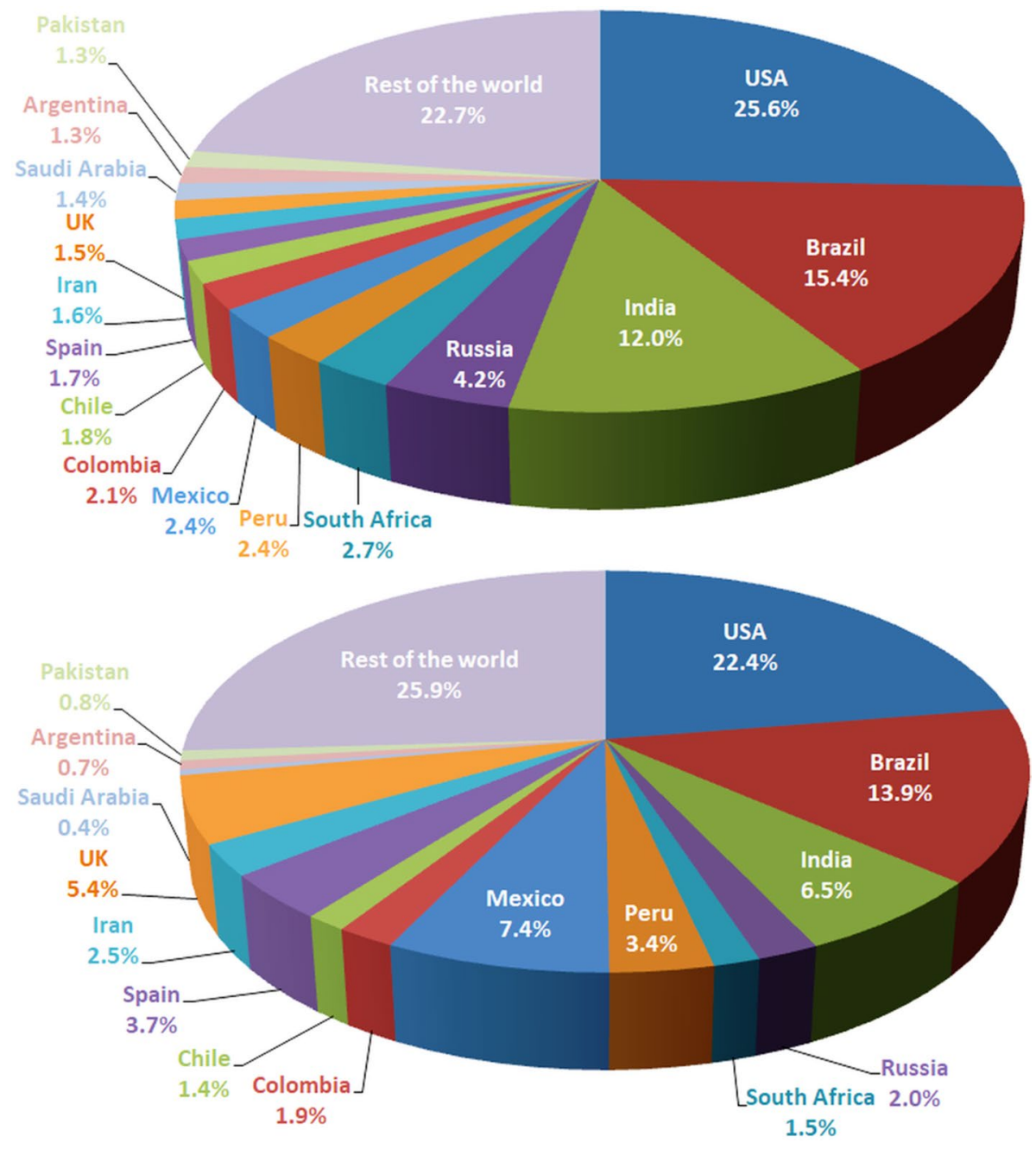

Fig. 4 Comparison of confirmed COVID-19 cases a and deaths b in India versus other countries ( Source: Coronavirus Worldometer, as of 15 August 2020)

death rate, in terms of case mortality and fatality rate, signifies timely clinical management and identification of the pandemic in India.

\subsection{State-wise spread of COVID-19}

As of 14 April 2020, the day when 21-day lockdown ended and GOI extended the Phase II of nationwide lockdown, India has reported 12,371 COVID-19 cases in 23 states/union territories (UTs) (MoHFW, GOI). These include 1509 patients that have been recovered/cured and 423 deaths. The major spike in the confirmed cases in India is linked to the Markaz event in Nizamuddin Cluster of New Delhi, which was reported on 1 April 2020 (WHO $2020 \mathrm{~g})$. Out of 14,378 total confirmed cases in India, 4291 cases $(29.8 \%)$ were linked to 
this event with a high burden of cases found in states including Tamil Nadu (83\%), Telangana (78\%), New Delhi (64\%), Uttar Pradesh (60\%), Andhra Pradesh (61\%) and fewer cases in other states (MoHFW, GOI).

Currently, the confirmed COVID-19 cases in India have crossed 2.5 million marks, out of which 1.5 million confirmed cases have been reported in the past 30 days. With this rapidly growing number of cases, India is now one of the major epicenters of the COVID-19 cases in the world. Table 3 (supplementary material) provides detailed information on the COVID-19 cases in India. Figure 5a, b shows the state-wise representation of confirmed
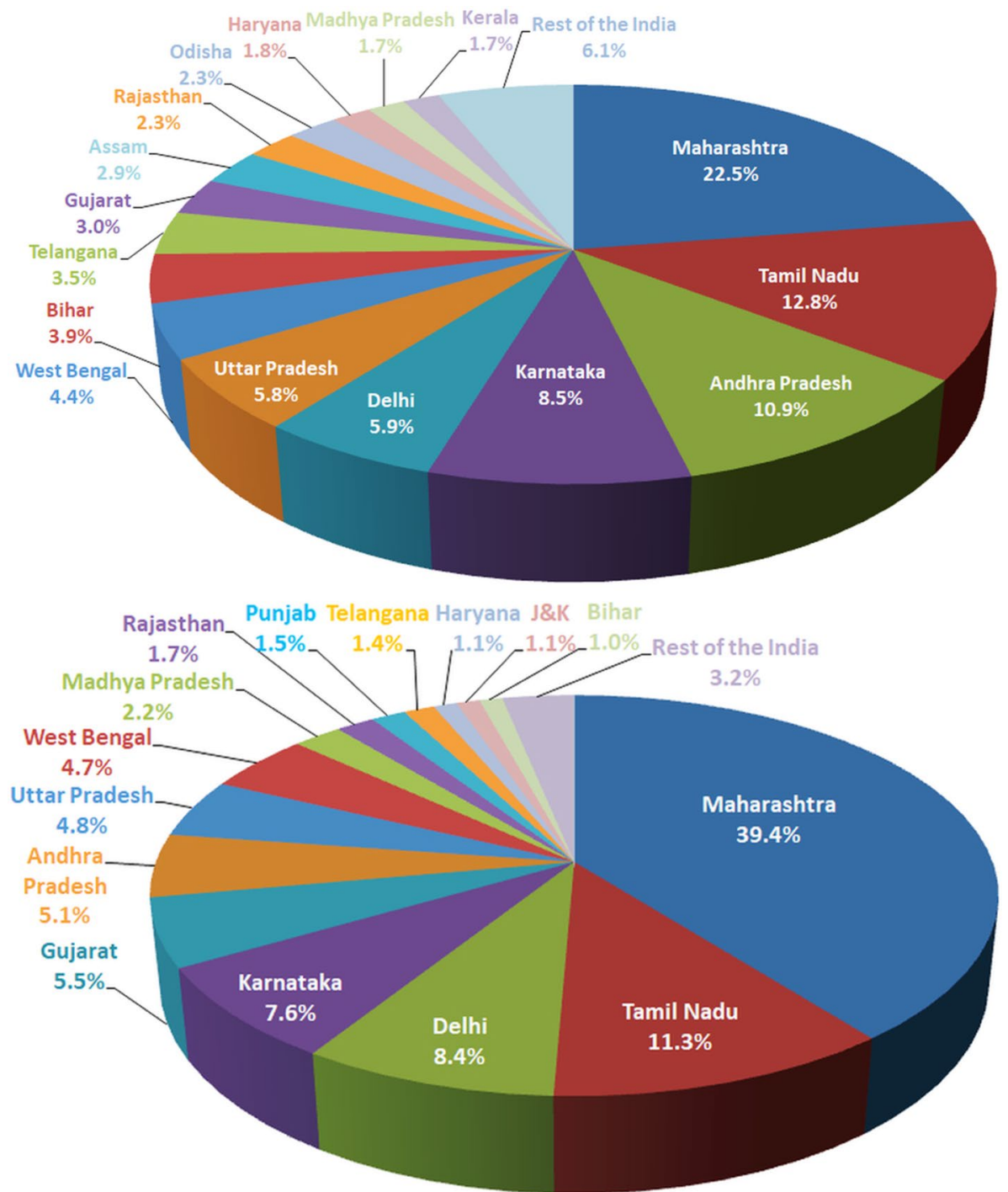

Fig. 5 State-wise representation of confirmed and deceased due to COVID-19 in India ( Source: MoHFW, as of 15 August 2020) 
and deceased cases due to COVID-19 in India. Among these states, Maharashtra, Tamil Nadu, Andhra Pradesh and Karnataka are the most affected states in India due to the pandemic and emerged as hotspots which account for $54.7 \%$ of India's active caseload. The maximum numbers of causalities are from Maharashtra, Tamil Nadu and Delhi, accounting for $59.1 \%$ of total deaths in the country.

Figure S2 (supplementary information) shows the trend of recovery rate, fatality rate and growth rate, reproduction number, doubling time and average days of hospitalization of COVID-19-infected patients in India. Figure S3 (supplementary information) shows the state/UTs-wise recovery and death rates due to COVID-19 in India. WHO has advised that a country needs 140 tests per day per million populations, while the national average of testing in India is 603 tests/day/million population (as of August 15), with focused efforts of the Centre and effective implementation by the states/UTs. At present, 24 states and UTs in India are conducting testing more than the national average of 15,119 tests per million, in which Goa leads with 84,927 tests per million, followed by Delhi having conducted 57,855 tests per million population. The growth rate of cases in India was 3.9\% for the 1 st 30 days (January 31-February 29) which rises to $21.3 \%$ for the 2nd 30 days (month of March), and afterward, there was declined trend in growth rate in consecutive days from 12 (month of April) to 5.8 (month of May) to 4\% (month of June) and 3.5\% for the month of July. The doubling time of cases in India improved from 3.4 days (the week before the Phase I of lockdown) to 9.7 days as of 1 May 2020. The analysis showed that the case fatality rate in India was $3.2 \%$ as on 30 April 2020, which includes $65 \%$ of male and $35 \%$ of female (MoHFW, GOI), and the case fatality rate decreased to 1.94\% (as of August 15) which is maintained below the global average and is on a continuous positive slide. The recovery rate of COVID-19 cases in India also improved from 22 (as on April 14) to $27.52 \%$ (as on May 4), 38.29\% (as on May 18), 48.19\% (as on June 1), 62.93\% (as on July 13 ) and $71.17 \%$ (as on August 15). The recovery rate of cases in India is constantly growing which reveals that almost 1 out of every 3 infected patients who were isolated or hospitalized have been recovered or cured. According to MoHFW, $50 \%$ of deaths have happened in the age group of 60 years and above; 37\% of deaths belong to 45-60 years age group, while $11 \%$ of deaths belong to $26-44$ years age group. This highlight the people above the age of 45 belong to the high-risk group and the country's containment strategy is focusing on this group. In the gender-wise distribution, $68 \%$ of people who died were men and $32 \%$ were women. Under the guidance and support of the GOI, all the states/UTs have taken lots of steps in this regard such as mapping of the communities and tracking of infected patients with the special attention towards the high-risk group like the population with co-morbidities and the aged/elderly persons and providing special care to these persons. The nationwide robust network of ANMs and ASHAs workers in addition to Ayushman Bharat-Health and Wellness Centers has assisted in effective contact tracing and surveillance of the infected persons, including the lakhs of returnees and migrants. Consequently, the fatality rate of almost 30 states/UTs has been found lower than the countrywide average. These data indicate that the early and aggressive measures taken by the GOI so far have shown encouraging results.

\subsection{Appraisal of COVID-19 related studies in India}

Various research groups have performed forecasting and data-driven mathematical modeling studies to predict the scenario of the COVID-19 situation in India. A study performed by Sardar et al. (2020) predicted the influence of a 3-week lockdown on COVID-19 in India 
and states like Maharashtra, Delhi and Telangana. As a result, they predicted that 3-week lockdown will not improve the situation of COVID-19 cases in India and in Maharashtra; however, Delhi and Telangana might witness a reduction in the deaths and confirmed cases due to the pandemic. Similarly, Singh and Adhikari (2020) also recommended that a 3 -week nationwide lockdown is inadequate to restrain the pandemic spread in India based on mathematical modeling. The study also proposed that physical distancing and agestructured played a vital role in the pandemic spread and suggested the periodic lockdowns with some relaxations for the containment of COVID-19. Senapati et al. (2020) proposed a mathematical model to envisage the mechanism of COVID-19 transmission between the persons for the reported cases during the period from 2 to 24 March 2020. The investigation exhibited that the proportion of symptomatic persons arising from the infected peoples was predicted to be $\geq 52 \%$, while the proportions of the quarantined and asymptomatic persons were predicted as $\geq 20 \%$ and $\geq 27 \%$, respectively. Hence, the contribution of the asymptomatic persons as well as a high reproduction number of 4.18 days due to the pandemic in India cannot be neglected. Forecasting and modeling study was conducted by Gupta and Pal (2020) from the period of 30 January 2020 (the day India reported its first case) to 24 March 2020 (the day GOI imposed Phase I of lockdown). These findings suggested that the confirmed cases of COVID-19 in India may extend to 700 thousand till April 30, and around 3 million people may get infected due to this virus if strict preventive measures are not taken in India. Exponential and susceptible-infected-recovered (SIR) models were used to predict the short- and long-term effect of COVID-19 in India based on the data till 30 March 2020 (Ranjan 2020). Based on the SIR model, India will enter equilibrium by the May end with the expected 13,000 confirmed cases of COVID-19. Results also suggested that the number of infected cases will significantly reduce after 8 April 2020 if physical distancing is promoted. Hussain et al. (2020) used the SIR model to study the impact of nationwide lockdown on the COVID-19 spread in India and projected that lockdown has reduced the infected cases by 23.65-337.73 lakhs in Class-I cities in India, where the pandemic has mostly spread. Roy and Kar (2020) discussed the nature of COVID-19 transmission in India by using the data till 10 April 2020. Analysis showed that as of now nature of growth of infected cases in India is following a linear growth and is nowhere near the exponential growth. The community spread and population density are key responsible factors to play a substantial role in the pandemic spread in India.

The prediction of the COVID-19 peak in India was studied using susceptible-exposed-infected-removed (SEIR) epidemiological model by incorporating the realtime date from the period of 29 February 2020 to 14 April 2020 (Belfin et al. 2020). The basic reproduction number for the pandemic was found to be 3.3 days in India, and the pandemic is anticipated to reach its peak by the month of September. However, according to the MoHFW, the pandemic peak is expected in July 2020. In another study, Tiwari (2020) used the SEIR model to understand the pandemic situation in India based on the real-time data until 7 April 2020. The model predicted that the reproduction number and doubling time of infected cases in India are 1.55 and 4.1 days, respectively. The results also suggested that India may witness 22 thousand cases till the end of April and the pandemic will finish in July in India. Chatterjee et al. (2020) employed the SEIR mathematical model to study the healthcare impact of the pandemic based on data till 21 March 2020. The findings of the model proposed that uninterrupted pandemic in India could have resulted in 1.56 million deaths and $>364$ million cases due to the pandemic which might reach its peak in mid-July. It was postulated that the immediate lockdown and nonpharmacological interventions can restrain the pandemic progress by April 2020 and reduce the cases of COVID-19, bringing down the total cases, ICU requirements, hospitalization and death by 
nearly $90 \%$. Mathematical modeling conducted by Tiwari et al. (2020) predicted that the outbreak of pandemic in India will be controlled by the end of May with a strict measures and aggressive lockdowns, and if the outbreak is not controlled by the end of May, then India may witness a shortage of health system and the situation will get worse. In another study, Patrikar et al. (2020) used the modified SEIR model to study the effect of social distancing in India. The results suggested that the pandemic curve will reach its peak in India in the third week of June with an approximate reproduction number of 1.8 days with the increase in hospitalization requirement, if transmissibility is high. According to Gopal et al. (2020), the combined efforts of government and individuals are important in reducing the population of infected cases and overall reducing the pandemic period as predicted by SEIR dynamic modeling. An extended version of SEIR was employed by Ray et al. (2020) to compare the effects of hypothetical durations of lockdown from an epidemiological perspective by using the daily basis data in India from March 1 to April 7. The results of this study suggested that a hypothetical lockdown of 28, 42 and 56-days could approximately prevent 285 thousand, 622 thousand and 781 thousand cases in India by June 15 , respectively. Mandal et al. (2020) addressed the critical role of community preparedness and the health system as a public health measure to control the pandemic spread in India. The mathematical model was used by Roy and Roy Bhattacharya (2020) to predict the pandemic spread in India by using the data from 1 March 2020 to 23 April 2020. The predictions found in this study are quite similar to the observed values recorded by GOI, and the model showed that the imposition of nationwide lockdown has played a significant role in restricting the spread of the pandemic. Kumar and Roy (2020) used the Bailey's mathematical model on the COVID-19 data from 1 March 2019 to 19 May 2020 and described that when the number of infected will be equal to a number of recovered from circulation by recovery and death, the coefficient will reach the $100 \%$ threshold and the pandemic will be extinguished in mid-September. However, due to the real-time and daily basis change in the data of COVID-19, the predictions of all these findings are expected to change accordingly. Besides, these models have several assumptions and uncertainties that were considered during the analysis which are far from what happens in reality. Hence, these findings should be merely considered for qualitative understanding and to predict the outspread behavior, but the usage of data is not worthwhile for any policy change or decision making and may not be considered for predicting the future.

\subsection{Preventive measures taken by India and future prospects}

GOI is pursuing its proactive and preemptive approach for management, prevention and containment of COVID-19 through collective efforts from states and UTs. The management efforts against the pandemic are being reviewed and monitored regularly at the highest level by MoHFW, ICMR and National Task Force (NTF) in collaboration with the WHO. MoHFW is rigorously and continuously working with states/UTs to strengthen the health infrastructure in the Country. For the containment of COVID-19, GOI has issued an order under the Disaster Management Act 2005 to impose the nationwide lockdown in a phased manner for strengthening the surveillance, building the capacity of the health delivery system and maintaining mandatory physical distancing. In this regard, all the states/UTs have been advised to strengthen their preventive measure including community surveillance, trained manpower, supply of adequate PPEs, isolation wards, quarantine and rapid response team to combat COVID-19. All the international travel and nationwide travel through road and railways were suspended in these lockdowns; however, the health 
services remained functional as per the guidelines of the Ministry of Home Affairs (MHA, GOI). All the travelers arriving in India from overseas are subject to 14-days of mandatory quarantine. The Ministry of Finance, GOI, has recently announced a special economic and comprehensive relief package of 200 billion USD (which 10\% of India's Gross Domestic Product) to support the economy's fight against COVID-19. The GOI has also come up with quick financial packages for developing laboratories, procuring more testing kits and improving the health service infrastructure in the country.

The MoHFW has come up with setting up of COVID-19 dedicated hospitals and planned for a more number of quarantine zones for the suspected and/or positive cases. A key component for the successful implementation of TESTING aggressively, TRACKING comprehensively and TREATING efficiently has ensured a rising recovery rate, which stands at $71.17 \%$ as on August 15. For the quality assurance of COVID-19 testing, 1465 laboratories and the National Institute of Virology (NIV), Pune of ICMR is the apex laboratory that is performing the testing of COVID-19. In collective efforts made by Central and State Governments, as many as 3231 dedicated COVID health centers, 1488 dedicated COVID hospitals and 10,755 COVID care centers with 14,59,278 isolation beds, 50,252 ICU beds and 1,83,249 oxygen supported beds are available from 1 August 2020 to combat COVID-19 in the country (MoHFW, GOI). Under the Essential Commodities Act 1955, the GOI issued an order to declare the hand sanitizers and face masks as an essential commodity for the management of COVID-19. Nearly 3 lakh N95 masks and 3 lakh Personal Protective Equipment (PPEs) coveralls are now being manufactured per day by $>300$ domestic producers. To date, the GOI has provided almost 3.04 crore N95 masks, 1.28 crore PPE kits and 23,346 "Make in India" ventilators to various states/UTs/central institutions at free of cost for the successful utilization of these preventive measures. Besides, to break the chain of transmission, GOI launched the mobile app "ArogyaSetu" in line with data security and privacy parameters to trace and monitor the movement of peoples to access their risk of COVID-19 infection. With the view of the management of COVID-19, all states have been asked to uniformly implement the containment plan in all the districts and to divide the districts into green, red and orange zones based on the growth rate of the COVID cases. As of May 22, out of 800 districts in India, 400 falls into the red zone, 200 falls into the orange zone, and 100 falls into the green zone (MoHFW, GOI).

WHO and MoHFW are collaboratively working to further strengthen the surveillance and response system based on transmission scenarios and providing the COVID-19 testing kits to dedicated laboratories through ICMR to meet their huge testing requirement. A realtime PCR test is recommended by ICMR for early diagnosis and clinical trials of plasma therapy have been commenced by ICMR (ICMR 2020a, 2020b). The testing capacity of COVID-19 in India has increased to approximately 8 lakh test per day from a total of 1465 laboratories (968 Government and 497 private) (MoHFW, GOI). Among these laboratories, 751 are real-time PCR-based, 597 are TrueNat-based and 117 are CBNAAT-based testing laboratories (as on 15 August 2020). Also, India's TEST, TRACK, TREAT strategy has achieved another peak with 8 lakh tests conducted by ICMR in a single day and taking the cumulative tests to 2.85 billion as on 15 August 2020. As of 1 April 2020, India was conducting 36 tests per million, which increased to 677 tests per million (as on May 1), 3505 tests per million as on 4 June 2020, 8396.4 tests per million as on 13 July 2020 and 21,213 tests per million population as on 15 August 2020 (MoHFW, GOI). According to ICMR, the use of hydroxychloroquine and Personal Protective Equipment (PPE) together may reduce the COVID-19 risk by $80 \%$. According to clinical management protocol for COVID-19, the usage of drug remdesivir has been encompassed as an "investigational therapy" only for limited emergency purposes (MoHFW, GOI). 
Speaking about vaccines, according to ICMR, the pandemic is progressing rapidly and to develop a vaccine, it needs time, not only in respect of science but also social, cultural and regulatory aspects. Presently, there are three vaccines in different phases of clinical trials. Firstly, ZyCov-DNA Vaccine by Zydus Cadila which has also completed Phase I studies in 11 sites and has started its Phase II trials. Secondly, COVAXIN by Bharat Biotech, Drug Controller General-CDSCO (The Central Drugs Standard Control Organization), vaccine has completed its Phase I safety and early efficacy studies in 11 sites, and its human trials have been approved by MHA, GOI. Thirdly, the Recombinant Oxford vaccine by Serum Institute of India, Pune, has been approved on 2 August 2020 for Phase I and II clinical trials to be started soon at 17 sites. However, till vaccines become available and even after, sustainable behavioral changes like physical distancing, wearing a mask, etc., should be maintained.

As the country is proceeding through the unlock phase, it is imperative to be aware of making proper behavior for COVID-19 an integral part of our daily life which will primarily include regular hand hygiene, the practice of face masks/covers, maintaining physical distancing, self-protection through boosting of immunity, taking care of the old and most vulnerable to the disease, installation of the Aarogya Setu app, following MoHFW guidelines and adopting a health-seeking behavior with on-time reporting of symptoms and care-seeking for COVID-19 treatment. It should be pointed out that the rate of testing should be conducted in municipal and slum areas to ensure the detection of cases at an early stage, reduction in the fatality rate and timely clinical management of infected persons. One threat to India's response to COVID-19 is the extent of misrepresentation of the pandemic driven by fear, stigma and blame. This also includes the growing level of violence against front-line health workers and stigmatization of COVID-19 confirmed or suspected, which could delay the reporting of illness. In this regard, a proficient initiative is required by multidisciplinary Indian researchers or scientists to curb the fake news, misinformation and to fight myths against the disease. There is also an urgent need of active coordination of GOI with private and government laboratories to address delays in sample collection, corporation with private hospitals to expand the bedding capacity, disinfection and proper waste disposal facilities in most affected and hotspot areas, camping for the management of travelers and migrant laborers, vigorously comprising youth groups, community leaders and NGOs in escorting surveillance teams for effective measures and provisioning of essential items and creating awareness in local languages regarding the stigmatization of patients and medical professionals. More private hospitals and laboratories should come up to support the government's efforts to combat the COVID-19 situation as the exponential growth in the cases may not give sufficient time to react to various offices and departments. Health workers should be trained for using the PPEs, screening of asymptomatic individuals, management and isolation measures of COVID-19 cases. The provision of proper health and life insurance must be provided to health workers if they get infected with COVID-19. Apart from focusing on the production of face masks and hand sanitizers, the specific research and development $(R \& D)$ centers should work on providing the best possible solution for medicines and vaccines against COVID-19, Ayurveda substitutes and preparing preventive kits. Globally, a lot of R\&D centers and pharmaceutical companies are in a race to prepare the vaccines against COVID-19, but to date, the situation looks worrying for the moment. As of now, physical distancing and maintaining personal hygiene are the best possible practice that should be followed by every individual to break the chain of transmission. There is a need for India to pay attention to its public healthcare system which is currently underfunded (1.28\% of GDP), making primary 
care weak. The outspread of the pandemic could be an obligatory wakeup call for India to strengthen its healthcare system for long-term changes.

\section{Conclusion}

The present study enlightens the current trend of contagious disease, COVID-19, in India. As of 15 August 2020, India has witnessed 12\% of the COVID-19 cases worldwide, with USA reporting one-fourth of the total number of cases. The mortality/million population in India is 36 deaths/lakh populations, which is lowest in comparison to the global case mortality rate of 98.7 deaths per lakh population. Currently, the confirmed COVID-19 cases in India have crossed 2.5 million marks, out of which 1.5 million confirmed cases have been reported in the past 30 days. With this rapidly growing number of cases, although India is now one of the major epicenters of the COVID-19 cases in the world, the recovery rate of cases in India is more than $70 \%$ which is continuously progressing. Moreover, the case fatality rate in India is $1.94 \%$ which is maintained below the global average and is on a continuous positive slide. However, with an average 60,000 cases per day, the flattening of the COVID-19 curve is nowhere in sight. The lockdown has been heavily criticized for its lack of planning, crippling economy, the migrant crisis and lack of proper strategy, which has led to the question whether a nationwide lockdown can break the transmission chain or just delays the peak of cases. The ease of lockdown will only increase the spread of the virus in India if the level of social distancing and personal hygiene is not maintained well until any potential vaccine is found to neutralize the virus. The government should design efficient and stringent intervention strategies in addition to lockdown like strong health infrastructure, reliable and timely testing of suspects and proper treatment mechanisms to control this pandemic in India in the containment zone. Even outside containment zones, all guidelines issued by the government on preventive measures should be followed. We believe that this study will provide insightful information in framing the policies to eradicate the COVID-19 in India.

Acknowledgements No funding or sponsorship was received for this study or publication of this article.

\section{Compliance with ethical standards}

Conflict of interest The authors declare that they have no conflict of interest.

Ethical approval None.

\section{References}

Araujo, M. B., \& Naimi, B. (2020). Spread of SARS-CoV-2 coronavirus likely to be constrained by climate. MedRxiv. https://doi.org/10.1101/2020.03.12.20034728.

Arora, A. S., Rajput, H., \& Changotra, R. (2020). Current perspective of COVID-19 spread across South Korea: Exploratory data analysis and containment of the pandemic. Environment, Development and Sustainability. https://doi.org/10.1007/s10668-020-00883-y.

Belfin, R. V., Brodka, P., Radhakrishnan, B., \& Rejula, V. (2020). COVID-19 peak estimation and effect of nationwide lockdown in India. MedRxiv. https://doi.org/10.1101/2020.05.09.20095919.

Bherwani, H., Nair, M., Musugu, K., Gautam, S., Gupta, A., Kapley, A., et al. (2020). Valuation of air pollution externalities: Comparative assessment of economic damage and emission reduction under 
COVID-19 lockdown. Air Quality, Atmosphere and Health. https://doi.org/10.1007/s11869-02000845-3.

Biswas, K., \& Sen, P. (2020). Space-time dependence of corona virus (COVID-19) outbreak. In arXiv: 2003.03149. https://arxiv.org/abs/2003.03149.

CDCP. (2020). Centers for Disease Control and Prevention. File: SARS-CoV-2 without background.png. Public Health Image Library (PHIL), with identification number \# 23312. https://phil.cdc.gov/Detai 1s.aspx?pid=23312.

Chan, J. F. W., Yuan, S., Kok, K. H., To, K. K. W., Chu, H., Yang, J., et al. (2020). A familial cluster of pneumonia associated with the 2019 novel coronavirus indicating person-to-person transmission: A study of a family cluster. The Lancet, 395, 514-523. https://doi.org/10.1016/S0140-6736(20)30154 -9 .

Chatterjee, K., Chatterjee, K., Kumar, A., \& Shankar, S. (2020). Healthcare impact of COVID-19 epidemic in India: A stochastic mathematical model. Medical Journal Armed Forces India, 76, 147155. https://doi.org/10.1016/j.mjafi.2020.03.022.

Chen, T. M., Rui, J., Wang, Q. P., Zhao, Z. Y., Cui, J. A., \& Yin, L. (2020). A mathematical model for simulating the phase-based transmissibility of a novel coronavirus. Infectious Diseases of Poverty, 9, 24. https://doi.org/10.1186/s40249-020-00640-3.

Chin, A., Chu, J., Perera, M., Hui, K., Yen, H.-L., Chan, M., et al. (2020). Stability of SARS-CoV-2 in different environmental conditions. MedRxiv. https://doi.org/10.1101/2020.03.15.20036673.

CoVW. (2020). Worldometer on coronavirus 2019. https://www.worldometers.info/coronavirus/.

De Wit, E., van Doremalen, N., Falzarano, D., \& Munster, V. J. (2016). SARS and MERS: Recent insights into emerging coronaviruses. Nature Reviews Microbiology, 14, 523-534. https://doi. org/10.1038/nrmicro.2016.81.

Din, M. A. U., \& Boppana, L. K. T. (2020). An update on the 2019-nCoV outbreak. American Journal of Infection Control, 48, 713. https://doi.org/10.1016/j.ajic.2020.01.023.

Ferguson, N. M., Laydon, D., Nedjati-Gilani, G., Imai, N., Ainslie, K., Baguelin, M., et al. (2020). Impact of non-pharmaceutical interventions (NPIs) to reduce COVID-19 mortality and healthcare demand. Imperial.Ac.Uk, (March). https://doi.org/10.25561/77482.

Funk, S., Ciglenecki, I., Tiffany, A., Gignoux, E., Camacho, A., Eggo, R. M., et al. (2017). The impact of control strategies and behavioural changes on the elimination of Ebola from Lofa County, Liberia. Philosophical Transactions of the Royal Society B: Biological Sciences. https://doi.org/10.1098/ rstb.2016.0302.

Gopal, R., Chandrasekar, V. K., \& Lakshmanan, M. (2020). Dynamical modelling and analysis of COVID-19 in India. In arXiv: 2005.08255. https://arxiv.org/abs/2005.08255.

Gupta, A., Bherwani, H., Gautam, S., Anjum, S., Musugu, K., Kumar, N., et al. (2020). Air pollution aggravating COVID-19 lethality? Exploration in Asian cities using statistical models. Environment, Development and Sustainability. https://doi.org/10.1007/s10668-020-00878-9.

Gupta, R., \& Pal, S. K. (2020). Trend analysis and forecasting of COVID-19 outbreak in India. MedRxiv. https://doi.org/10.1101/2020.03.26.20044511.

Gupta, S., \& Shankar, R. (2020). Estimating the number of COVID-19 infections in Indian hot-spots using fatality data. In arXiv. https://arxiv.org/abs/2004.04025.

Hellewell, J., Abbott, S., Gimma, A., Bosse, N. I., Jarvis, C. I., Russell, T. W., et al. (2020). Feasibility of controlling COVID-19 outbreaks by isolation of cases and contacts. The Lancet Global Health, 8, e488-e496. https://doi.org/10.1016/S2214-109X(20)30074-7.

Husain, Z., Das, A. K., \& Ghosh, S. (2020). Did the national lockdown lock COVID-19 down in India, and reduce pressure on health infrastructure? MedRxiv. https://doi.org/10.1101/2020.05.27.20115 329.

ICMR. (2020a). Advisory on rapid antibody tests. https://www.icmr.gov.in/pdf/covid/strategy/Revised_ Advisory_Rapid_Anibody_blood_tests.pdf.

ICMR. (2020b). ICMR initiates plasma therapy clinical trials. https://www.thehindubusinessline.com/ news/science/icmr-initiates-plasma-therapy-clinical-trials/article31518634.ece.

ICMR. (2020). Indian council of medical research, New Delhi, Government of India. https://covid.icmr. org.in/index.php.

ISI. (2020). Researchers responding to COVID-19. In Indian Statistical Institute. https://www.isical.ac. in/ covid19/index.html.

JHGR. (2020). John Hopkins GitHub repository on Coronavirus 2019. https://github.com/CSSEGISand Data/COVID-19/.

Kucharski, A. J., Russell, T. W., Diamond, C., Liu, Y., Edmunds, J., Funk, S., et al. (2020). Early dynamics of transmission and control of COVID-19: A mathematical modelling study. The Lancet Infectious Diseases, 20, 553-558. https://doi.org/10.1016/S1473-3099(20)30144-4. 
Kumar, A., \& Roy, R. (2020). Application of mathematical modeling in public health decision making pertaining to control of COVID-19 pandemic in India. Epidemiology International, 5, 23-26. https://doi. org/10.24321/2455.7048.202013.

Li, Q., Guan, X., Wu, P., Wang, X., Zhou, L., Tong, Y., et al. (2020). Early transmission dynamics in Wuhan, China, of novel coronavirus-infected pneumonia. New England Journal of Medicine, 382, 1199-1207. https://doi.org/10.1056/NEJMoa2001316.

Luo, W., Majumder, M. S., Liu, D., Poirier, C., Mandl, K. D., Lipsitch, M., et al. (2020). The role of absolute humidity on transmission rates of the COVID-19 outbreak. MedRxiv. https://doi. org/10.1101/2020.02.12.20022467.

Mandal, S., Bhatnagar, T., Arinaminpathy, N., Agarwal, A., Chowdhury, A., Murhekar, M., et al. (2020). Prudent public health intervention strategies to control the coronavirus disease 2019 transmission in India: A mathematical model-based approach. The Indian Journal of Medical Research, 151, 190. https://doi.org/10.4103/ijmr.IJMR_504_20.

MoHFW. (2020). Ministry of Health and Family Welfare, Government of India. Retrieved June 6, 2020 from https://www.mohfw.gov.in/index.php/.

Patrikar, S., Poojary, D., Basannar, D. R., \& Kunte, R. (2020). Projections for novel coronavirus (COVID19) and evaluation of epidemic response strategies for India. Medical Journal Armed Forces India. https://doi.org/10.1016/j.mjafi.2020.05.001.

PHFI. (2020). PHFI and IIPHs working for Covid-19. Public Health Foundation of India. https://phfi.org/ covid19/.

Rajput, H., Changotra, R., Rajput, P., Gautam, S., Gollakota, A. R., \& Arora, A. S. (2020). A shock like no other: Coronavirus rattles commodity markets. Environment, Development and Sustainability. https:// doi.org/10.1007/s10668-020-00934-4.

Ranjan, R. (2020). Predictions for COVID-19 outbreak in India using epidemiological models. MedRxiv. https://doi.org/10.1101/2020.04.02.20051466.t.

Ray, D., Salvatore, M., Bhattacharyya, R., Wang, L., Mohammed, S., Purkayastha, S., et al. (2020). Predictions, role of interventions and effects of a historic national lockdown in India's response to the COVID-19 pandemic: Data science call to arms. MedRxiv. https://doi.org/10.1101/2020.04.15.20067 256.

Richman, D. D., Whitley, R. J., \& Hayden, F. G. (2016). Clinical virology (4th ed.). Washington: ASM Press.

Riley, S., Fraser, C., Donnelly, C. A., Ghani, A. C., Abu-Raddad, L. J., Hedley, A. J., et al. (2003). Transmission dynamics of the etiological agent of SARS in Hong Kong: Impact of public health interventions. Science, 300, 1961-1966. https://doi.org/10.1126/science.1086478.

Robertson, P. (2020). Size of coronavirus particle PM2.5 and bacteria. https://smartairfilters.com/en/blog/ can-air-purifiers-filter-out-the-coronavirus/.

Roy, A., \& Kar, S. (2020). Nature of transmission of Covid19 in India. Medrxiv. https://doi. org/10.1101/2020.04.14.20065821.

Roy, S., \& Roy Bhattacharya, K. (2020). Spread of COVID-19 in India: A mathematical model. SSRN Electronic Journal. https://doi.org/10.2139/ssrn.3587212.

Sajadi, M. M., Habibzadeh, P., Vintzileos, A., Shokouhi, S., Miralles-Wilhelm, F., \& Amoroso, A. (2020). Temperature and latitude analysis to predict potential spread and seasonality for COVID-19. SSRN Electronic Journal. https://doi.org/10.2139/ssrn.3550308.

Sardar, T., Nadim, S. S., \& Chattopadhyay, J. (2020). Assessment of 21 days lockdown effect in some states and overall India: A predictive mathematical study on COVID-19 outbreak. In arXiv. https://arxiv.org/ abs/2004.03487

Senapati, A., Rana, S., Das, T., \& Chattopadhyay, J. (2020). Impact of intervention on the spread of COVID19 in India: A model based study. In arXiv. https://arxiv.org/abs/2004.04950.

Shen, M., Peng, Z., Xiao, Y., \& Zhang, L. (2020). Modelling the epidemic trend of the 2019 novel coronavirus outbreak in China. BioRxiv. https://doi.org/10.1101/2020.01.23.916726.

Singh, R., \& Adhikari, R. (2020). Age-structured impact of social distancing on the COVID-19 epidemic in India. In arXiv.https://arxiv.org/abs/2003.12055.

Sun, N., Shi, S., Jiao, D., Song, R., Ma, L., Wang, H., et al. (2020). A qualitative study on the psychological experience of caregivers of COVID-19 patients. American Journal of Infection Control, 48, 592-298. https://doi.org/10.1016/j.ajic.2020.03.018.

Tang, B., Wang, X., Li, Q., Bragazzi, N. L., Tang, S., Xiao, Y., et al. (2020). Estimation of the transmission risk of the 2019-nCoV and Its implication for public health interventions. Journal of Clinical Medicine, 9, 462. https://doi.org/10.3390/jcm9020462.

Tiwari, A. (2020). Modelling and analysis of COVID-19 epidemic in India. MedRxiv. https://doi. org/10.1101/2020.04.12.20062794. 
Tiwari, S., Kumar, S., \& Guleria, K. (2020). Outbreak trends of corona virus (COVID-19) in India: A prediction. Disaster Medicine and Public Health Preparedness. https://doi.org/10.1017/dmp.2020.115.

Wathore, R., Gupta, A., Bherwani, H., \& Labhasetwar, N. (2020). Understanding air and water borne transmission and survival of coronavirus: Insights and way forward for SARS-CoV-2. Science of the total environment, 141486. https://www.sciencedirect.com/science/article/pii/S0048969720350154.

Wang, J., Tang, K., Feng, K., \& Lv, W. (2020). High temperature and high humidity reduce the transmission of COVID-19. SSRN Electronic Journal. https://doi.org/10.2139/ssrn.3551767.

Wang, M., Jiang, A., Gong, L., Luo, L., Guo, W., Li, C., et al. (2020). Temperature significant change COVID-19 transmission in 429 cities. MedRxiv. https://doi.org/10.1101/2020.02.22.20025791.

WHO. (2020a) Coronavirus disease 2019 (COVID-19) situation report-41. World Health Organization. https://www.who.int/docs/default-source/coronaviruse/situation-reports/20200301-sitrep-41-covid-19. pdf?sfvrsn=6768306d_2.

WHO. (2020b). Q and A on coronaviruses (COVID-19). World Health Organization. https://www.who.int/ emergencies/diseases/novel-coronavirus-2019/question-and-answers-hub/q-a-detail/q-a-coronaviruses.

WHO. (2020c) Advice on the use of masks in the context of COVID-19. World Health Organization. https :/www.who.int/publications-detail/advice-on-the-use-of-masks-in-the-community-during-home-careand-in-healthcare-settings-in-the-context-of-the-novel-coronavirus-(2019-ncov)-outbreak.

WHO. (2020d). India situation update report-14. World Health Organization. https://www.who.int/docs/ default-source/wrindia/situation-report/india-situation-report-14.pdf?sfvrsn=9a742871_2.

WHO. (2020e). India situation update report-7. World Health Organization. https://www.who.int/docs/defau 1t-source/wrindia/situation-report/india-situation-report-14.pdf?sfvrsn=9a742871_2.

WHO. (2020f). Coronavirus disease (COVID-2019) situation reports-138. World Health Organization. https ://www.who.int/docs/default-source/coronaviruse/situation-reports/20200606-covid-19-sitrep-138. pdf?sfvrsn=c8abfb17_4.

WHO. (2020g). India situation update report-11. World Health Organization. https://www.who.int/docs/ default-source/wrindia/situation-report/india-situation-report-11.pdf?sfvrsn=f7646851_2.

WHO. (2020). Naming the coronavirus disease (COVID- 19) and the virus that causes it. World Health Organization. Retrieved June 72020 from https://www.who.int/emergencies/diseases/novel-coronaviru s-2019/technical-guidance/.

Wu, F., Zhao, S., Yu, B., Chen, Y. M., Wang, W., Song, Z. G., et al. (2020). A new coronavirus associated with human respiratory disease in China. Nature, 579, 265-269. https://doi.org/10.1038/s4158 6-020-2008-3.

Zhou, P., Yang, X. L., Wang, X. G., Hu, B., Zhang, L., Zhang, W., et al. (2020). A pneumonia outbreak associated with a new coronavirus of probable bat origin. Nature, 579, 270-273. https://doi.org/10.1038/ s41586-020-2012-7.

Zhu, N., Zhang, D., Wang, W., Li, X., Yang, B., Song, J., et al. (2020). A novel coronavirus from patients with pneumonia in China, 2019. New England Journal of Medicine, 382, 727-733. https://doi. org/10.1056/NEJMoa2001017.

Publisher's Note Springer Nature remains neutral with regard to jurisdictional claims in published maps and institutional affiliations.

\section{Affiliations}

\section{Rahil Changotra ${ }^{1} \cdot$ Himadri Rajput ${ }^{1} \cdot$ Prachi Rajput $^{2} \cdot$ Sneha Gautam $^{3}$. Amarpreet Singh Arora ${ }^{4}$ iD}

1 School of Energy and Environment, Thapar Institute of Engineering and Technology, Patiala 147004, India

2 Central Scientific Instruments Organization, Sector 30C, Chandigarh 160030, India

3 Karunya Institute of Technology and Sciences, Coimbatore 641114, Tamil Nadu, India

4 School of Chemical Engineering, Yeungnam University, Gyeongsan 38541, South Korea 